\title{
Refractory hyperactive bladder treated with sacral neuromodulator: case report and literature review
}

\author{
Junior J. Araiza Navarro ${ }^{1 *}$, Raúl D. Lara Sánchez ${ }^{1}$, Oyuki A. Morales Uscanga ${ }^{2}$, \\ María I. Tolentino Sosa ${ }^{3}$, Fernando López Reyes ${ }^{4}$, Jorge A. Barbabosa Vilchis ${ }^{5}$
}

\begin{abstract}
${ }^{1}$ Gynecology and Obstetrics Resident at the Postgraduate School of Naval Sanity, Universidad Naval and the Hospital General Naval de Alta Especialidad, Secretaría de Marina Armada de México (SEMAR)

${ }^{2}$ Gynecologist-Obstetrician, Chief of Residents the Surgical Area of the Hospital General Naval de Alta Especialidad, Secretaría de Marina Armada de México (SEMAR)

${ }^{3}$ Gynecologist-Obstetrician, Gynecological Urology, Chief of the Urogynecology Service of the Hospital General Naval de Alta Especialidad, Secretaría de Marina Armada de México (SEMAR)

${ }^{4}$ Urologist, Kidney Transplant Specialist of the Hospital General Naval de Alta Especialidad, Secretaría de Marina Armada de México (SEMAR)

${ }^{5}$ Gynecologist-Obstetrician, Colposcopist, Chief of the Department of Gynecology and Obstetrics of the Hospital General Naval de Alta Especialidad, Secretaría de Marina Armada de México (SEMAR)
\end{abstract}

Received: 02 May 2018

Accepted: 29 May 2018

\section{*Correspondence:}

Dr. Junior J. Araiza Navarro,

E-mail: joelara16@hotmail.com

Copyright: (c) the author(s), publisher and licensee Medip Academy. This is an open-access article distributed under the terms of the Creative Commons Attribution Non-Commercial License, which permits unrestricted non-commercial use, distribution, and reproduction in any medium, provided the original work is properly cited.

\begin{abstract}
The overactive bladder syndrome is a chronic medical condition that affects the quality of life of patients whether men or women, has a prevalence of $16.5 \%$, however, it is known to increase with age, affecting up to $25 \%$ of women older than 65 years and up to $80 \%$ in the elderly. More than $90 \%$ of cases have no apparent cause. The OAB (Overactive Bladder) It is a condition with characteristic symptoms of urinary urgency, usually accompanied by frequency and nocturia, with or without urge incontinence, in the absence of urinary tract infection or other obvious pathology. The different therapeutic steps are not always sufficient to restore the quality of life.
\end{abstract}

Keywords: Detrusor overactivity, Sacral neuromodulator, Urinary incontinence, Urodynamics

\section{INTRODUCTION}

The Overactive Bladder is a urogenital syndrome which can be accompanied by urinary urgency or not. The $\mathrm{OAB}$ is usually associated with chronic inflammatory processes of the bladder, obstructive disorders, antecedents of vaginal deliveries, obesity, postmenopause and advanced age. Some neurological diseases usually manifest with Overactive Bladder (OAB). ${ }^{1,2}$

The diagnosis of this pathology is clinical, presenting urgency, frequency and nocturia, with or without urinary incontinence. The Urodynamic study detects $60 \%$ of hyperactive detrusor in patients with a diagnosis of OAB. The study of urodynamics involves evaluating the transport, storage and emptying of urine, is considered an invasive procedure which is not exempt from complications and discomfort to the patient, measures different variants such as postvoid residue, uroflowmetry, cystometry, videourodynamics and urethral function tests. ${ }^{3,4}$ The initial approach in the patient with suspected Overactive Bladder will be to obtain a complete clinical history, evaluate the symptomatology, the degree of discomfort and its impact on their lifestyle. ${ }^{3}$

The European Association of Urology and the Japanese Society of Urology mention the non-pharmacological, 
pharmacological and surgical treatment (electrostimulation) for the Idiopathic Overactive Bladder, according to the severity of the symptoms and the response to each line of treatment. ${ }^{5,6}$

The non-pharmacological treatment of the Overactive Bladder consists of educating the patient and helping them to use strategies to reduce the symptoms, these consist of changes in lifestyle, pelvic floor exercises and bladder training. ${ }^{7-9}$

In pharmacological treatment anticholinergic drugs are used to achieve some relaxation of the detrusor muscle, this class of drugs are recommended by the Oxford guides. ${ }^{10}$

When the action of these drugs is not enough to provide improvement of symptoms, you can opt for another line of treatment before reaching the most invasive management, such as the injection of botulinum toxin in the detrusor muscle. ${ }^{11}$

In the most severe cases of Overactive Bladder refractory to treatment, sacral stimulation in the S3 nerve root with a device implanted in this region that emits electrical impulses, can provide improvement in the symptoms of urinary frequency and urgency. ${ }^{12}$

As a last resort, enterocystoplasty has been used, which consists of increasing the size of the bladder by adding it to its intraluminal surface with the interposition of a loop of small intestine or stomach, however, this is an expensive surgical procedure with many side effects. ${ }^{13}$

\section{CASE REPORT}

A 62-year-old patient attending the Gynecology service of the High Specialty Naval General Hospital (HOSGENAES) in February 2015; Referring begins 4 years ago with symptoms of severe overactive bladder.

It has a history of importance: Surgical: bilateral tubal occlusion in 1996, vaginal plasty by prolapse in 1997; Chronic-degenerative diseases: pulmonary bronchiectasis secondary to tuberculosis in 1998; Gynecological Background: menarche: 14 years, family planning method: bilateral tubal occlusion in 1996, pregnancy 2, births 2, fetus with greater weight of $3900 \mathrm{gr}$, menopause at 50 years; rest of denied background.

Patient who refers daytime urinary frequency: 15 times and nocturnal urinary frequency: 3 times, with a fluid intake of 3 liters/ day. Emergency urinary incontinence $(+)$, urinary loss in jet 10 times a day, change of towels 6 times a day. Physical examination with normal perineal reflexes, Perineal insufficiency: 2, Gossling 2, Valsalva and cough (-), without prolapse of pelvic organs. The following laboratory and cabinet studies were taken: Bladder ultrasound: no structural pathology, with residual urine less than $10 \%$.
Urodynamics: flowmetry: volume $130 \mathrm{ml} / \mathrm{min}$ without residual urine, profilometry: maximum urethral closure pressure (PMCU) of $69 \mathrm{~cm} \mathrm{H} 2 \mathrm{O}$, functional profile length of $1.5 \mathrm{~cm}$, cystometry: maximum detrusor pressure of $20 \mathrm{~cm} \mathrm{H}_{2} \mathrm{O}$, voiding volume $133 \mathrm{ml}$, urine residual 14 $\mathrm{ml}$, with detrusor activity during cystometry, premature bladder sensations; with urodynamic diagnosis of Detrusor Overactive, Cystoscopy: normal, negative urine culture.

First line treatment with oxybutynin-based anticholinergic drugs of 5 and $10 \mathrm{mg}$ daily and lifestyle changes was initiated for 6 months without improvement, then treatment with TENS (Transcutaneous Electrical Nerve Stimulation) with a vaginal electrode for 12 sessions was started. With improvement of the symptoms of $50 \%$ at the $4^{\text {th }}$ session, so therapy is continued until the 12 sessions are over, with relapse at the end of sessions, so it is decided to start second-line therapy, administering $200 \mathrm{U}$ of Botulinum Toxin A with partial improvement and transient, showing relapse at 3 months.

Subsequently evaluated by urology service, who decides to program for sacral neuromodulator test placement; This procedure is performed on March 13, 2017.

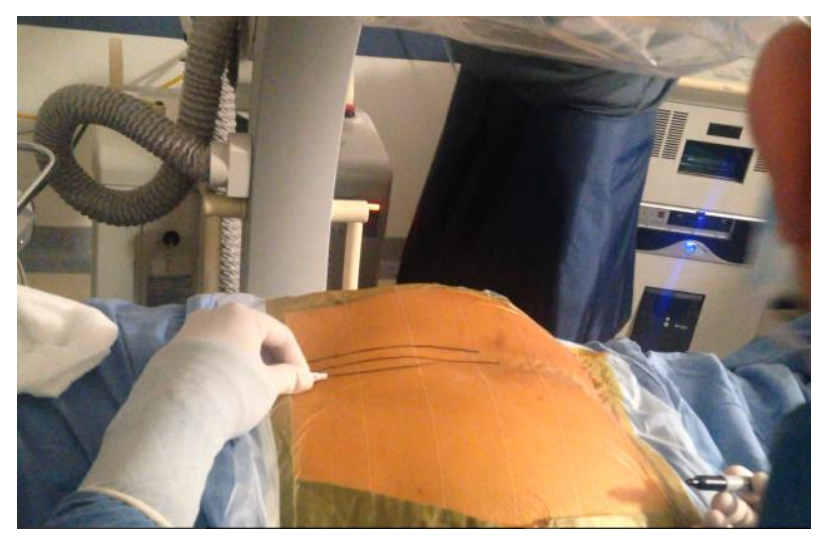

Figure 1: Marking at the level of hole S3.



Figure 2: Needle at S3 level.

Placement of the sacral neuromodulator (Medtronic Inter Stim II): The first stage was carried out under general anesthesia in decubitus prone, hole S3 was searched and 
marked, needle was placed in this site with continuous fluoroscopy. Both sides were stimulated until finding the best perineal and perianal contraction response in the right S3 hole. A permanent electrode was placed on the $\mathrm{S} 3$ root and connected to the external pulse generator (Figure 1 to 4 ).

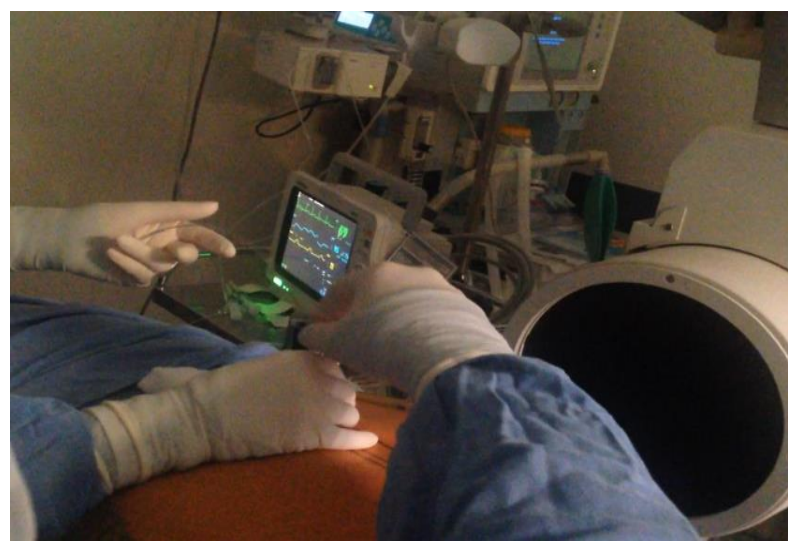

Figure 3: Placement of the definitive catheter at the level of the S3 hole.

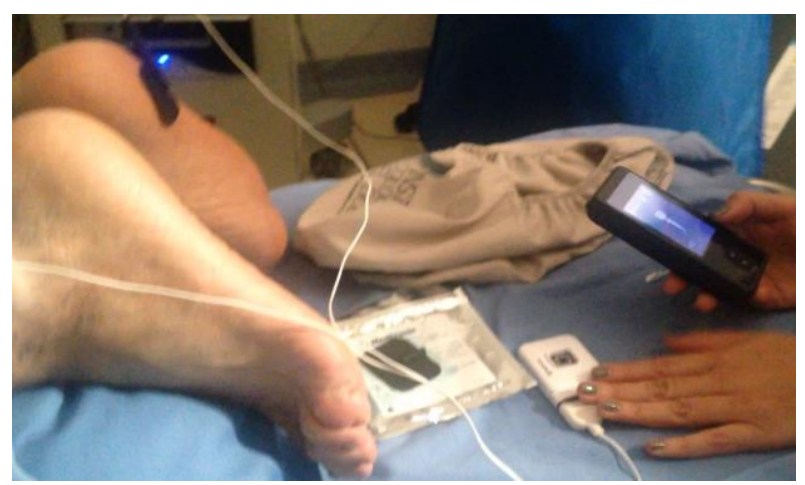

Figure 4: External stimulator voltage modulation.

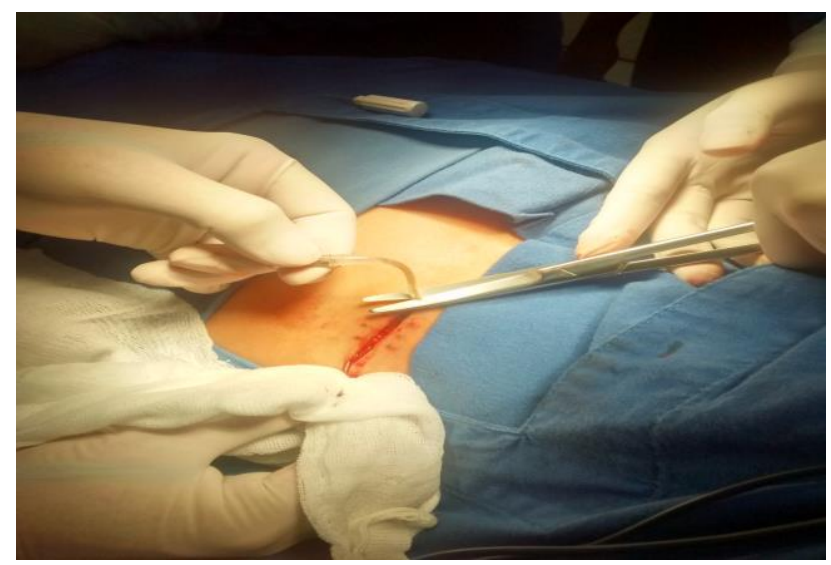

Figure 5: Definite electrode length adjustment.

Two weeks later, the second stage was carried out in which the impulse generator (Medtronic Inter Stim II) was implanted in a definitive manner, which was placed under local anesthesia and sedation, making a transverse incision at the level of the external superior quadrant of the right buttock. at the height of S3, dissecting subcutaneous cellular tissue until finding a permanent electrode which is disconnected from the external pulse generator and connected to the definitive pulse generator (Medtronic Inter Stim II), the parameters of the sacral neuromodulator are adjusted without complications and proceeds to close subcutaneous cellular tissue and skin (Figure 5 to 8 ).

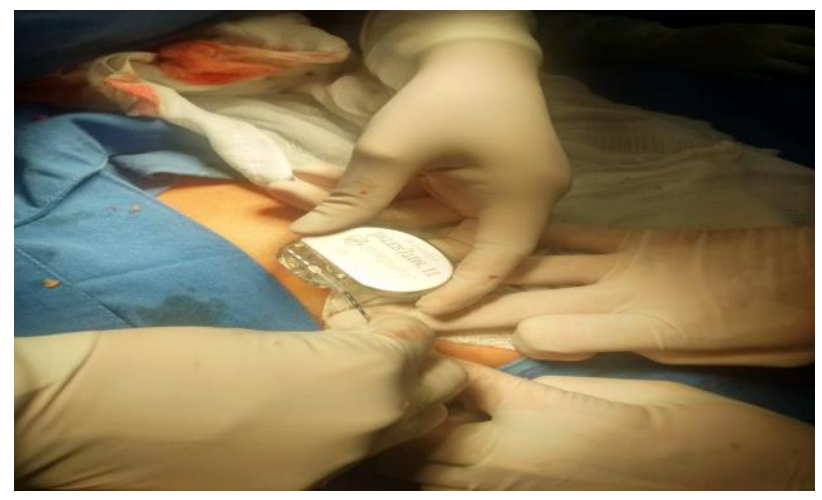

Figure 6: Connection of the electrode with the neuromodulator.

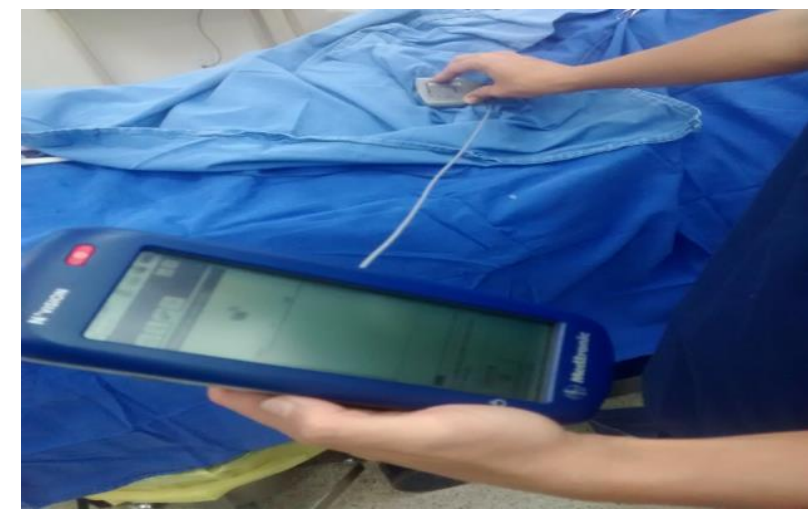

Figure 7: Neuromodulator voltage adjustment.

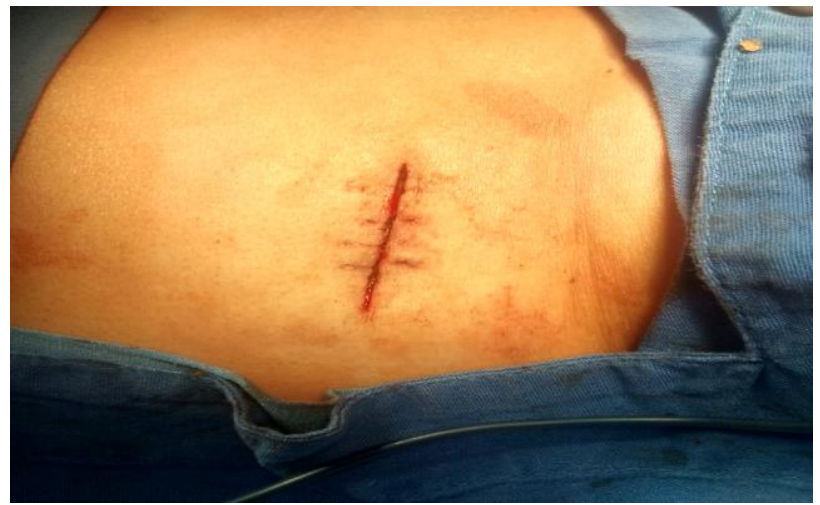

Figure 8: Incision at the level of hole $\mathrm{S3}$ in the right gluteus.

Patient who presents improvement after surgical procedure in $90 \%$, with daytime urinary frequency of 6 
times and nocturnal urinary frequency 1 time, with urinary incontinence of urgency in 1 occasion to the month in small jet.

Currently, after 1 year, the patient continues with a good response to treatment.

\section{DISCUSSION}

The overactive bladder syndrome is a chronic medical condition that, if not treated, evolves in a negative manner, causing, with the degree of the symptoms, a worsening in the quality of life. Although the prevalence is estimated at approximately $16.5 \% .{ }^{14}$. This figure may be underestimated, since it is estimated that many patients do not reach the outpatient gynecological urology due to embarrassment or ignorance. The cardinal symptom in Hyperactive Bladder Syndrome is urgency and nocturia is reported by patients as the most annoying symptom, causing sleep disorders, which is not repairing, and cases of depression have been reported, mainly in the elderly population. ${ }^{15-17}$

For the pathophysiology of overactive bladder syndrome, it has been postulated that several factors may be involved, although the main cause will vary from individual to individual. The exact mechanism of why the overactive bladder develops is not entirely clear, however, several authors have proposed the following 4 theories:

- The neurogenic theory: Which proposes that the micturition reflex is triggered by the reduction of the inhibitory neuronal impulses and the increase of the afferent impulses of the bladder. ${ }^{18}$

- Autonomic bladder theory: The alteration or exacerbation of phasic activity is generated by muscarinic activation. ${ }^{19}$

- The myogenic theory: Here it is thought that the detrusor muscle becomes more sensitive to cholinergic stimulation, causing an increase in the spontaneous activity of this muscle. ${ }^{20}$

- The theory of afferent signaling: Here the filling of the bladder sends increased afferent signals, causing with this the spontaneous contraction of the bladder. ${ }^{21}$

Within the treatment for overactive bladder syndrome, sacral neuromodulation is an accepted therapy, although not only to provide benefits to overactive bladder syndrome, but also has its use in fecal incontinence, chronic pelvic pain and vulvodynia. Despite more than 20 years of experience in developed countries, it remains a specialized and non-standardized procedure. Used for cases of severe overactive bladder or that has not improved with non-pharmacological and pharmacological treatment, including the application of botulinum toxin A directly on the detrusor muscle. ${ }^{22}$
In the patient, all the therapeutic lines available in the hospital and those that mark international literature such as behavioral therapy, bladder exercises, antimuscarinics and even the use of botulinum toxin $\mathrm{A}$ in the detrusor were exhausted. The patient had a significant deterioration of the quality of life, since, due to nocturia, the sleep was not repairing, after the placement of the Inter Stim II sacrum neuromodulator, there was an improvement of more than $90 \%$ of the urinary symptoms, mainly of frequency, urgency and nocturia. One year after the placement of the device, the patient continues to report only 1-2 emergency events per month, a condition that has significantly improved their quality of life.

\section{CONCLUSION}

The overactive bladder syndrome is a disease with a high prevalence in women which increases according to age, the diagnosis in most cases is clinical, although sometimes it is necessary to perform a urodynamic study to confirm, there are several lines of treatment, the response to each of them will consist of the etiology and the severity of the symptoms, the sacral neuromodulation has proved useful when the other lines of treatment have not been successful.

\section{Funding: No funding sources}

Conflict of interest: None declared

Ethical approval: The study was approved by the Institutional Ethics Committee of HOSGENAES

\section{REFERENCES}

1. de Boer TA, Slieker-ten Hove MCP, Burger CW, Vierhout ME. The prevalence and risk factors of overactive bladder symptoms and its relation to pelvic organ prolapse symptoms in a general female population. Int Urogynecol J. 2011;22(5):569-75.

2. Irwin DE, Milsom I, Hunskaar S, Reilly K, Kopp Z, Herschorn $S$, et al. Population-based survey of urinary incontinence, overactive bladder, and other lower urinary tract symptoms in five countries: results of the EPIC study. Eur Urol. 2006;50(6):1306

3. Vo A, Kielb SJ. Female voiding dysfunction and urinary incontinence. Med Clinics N Am. 2017 Dec 20. Available at: org/10.1016/j.mcna.2017.10.006

4. Musco S, PadillaFernández B, Del Popolo G, Bonifazi M, Blok BF, Groen J, et al. Value of urodynamic findings in predicting upper urinary tract damage in neuro-urological patients: A systematic review. Neurourol Urodynam. 2018;1-19. Available at: https://doi.org/10.1002/nau.23501.

5. Thuroff JW, Abrams P, Andersson KE, Artibani W, Chapple CR, Drake MJ, et al. EAU Guidelines on Urinary Incontinence. Actas Urol Esp. 2011;35:37388.

6. Yamaguchi O, Nishizawa O, Takeda M, Yokoyama O, Homma Y, Kakizaki H, et al. Clinical guidelines for overactive bladder. Int J Urol. 2009;16:126-42. 
7. Hashim H, Abrams P. How should patients with an overactive bladder manipulate their fluid intake? BJU Int. 2008 Jul 1;102(1):62-6.

8. Lohsiriwat S, Hirunsai M, Chaiyaprasithi B. Effect of caffeine on bladder function in patients with overactive bladder symptoms. Urol Annals. 2011;3(1):14-8.

9. Shafik A, Shafik IA. Overactive bladder inhibition in response to pelvic floor muscle exercises. World J Urol. 2003 May 1;20(6):374-7.

10. Robinson D, Cardozo L. Antimuscarinic drugs to treat overactive bladder. BMJ. 2012 Mar 27;344:e2130. Available at: 10.1136/bmj.e2130

11. Schmid DM, Sauermann P, Werner M, Schuessler B, Blick N, Muentener M, et al. Experience with 100 cases treated with botulinum-A toxin injections in the detrusor muscle for idiopathic overactive bladder syndrome refractory to anticholinergics. J Urol. 2006; 176:177-85.

12. Van Kerrebroeck PE, van Voskuilen AC, Heesakkers JP, Lycklama á Nijholt AA, Siegel S, Jonas U, et al. Results of sacral neuromodulation therapy for urinary voiding dysfunction: results of a prospective clinical study worldwide. J Urol. 2007;178:2029-34.

13. Somani BK, Kumar V, Wong S, Pickard R, Ramsay C, Nabi G, et al. Bowel dysfunction after transposition of intestinal segments into the urinary tract: 8-year prospective cohort. J Urol. 2007; 177:1793-8.

14. Stewart W, Van Rooyen J, Cundiff G, Abrams P, Herzog A, Corey R, et al. Prevalence and burden of overactive bladder in the United States. World $\mathrm{J}$ Urol. 2003 May 1;20(6):327-36.

15. Middelkoop HA, Smilde-van den Doel DA, Neven AK, Kamphuisen HA, Springer CP. Characteristics of the subjective sleep of 1,485 men and women aged 50 to 93 years: effects of sex and age, and factors related to the self-rated quality of sleep. J Gerontol Biol Sci Med Sci. 1996;51:M108-15 PMID: 8630703.

16. Van der Vaart CH, Roovers JP, de Leeuw JR, Heintz AP. Association between urogenital symptoms and depression in community -dwelling women aged 20 to 70 years. Urol. 2007;69:691-6.

17. Abrams P. Nocturia: the effect on sleep and related health consequences. Europ Urol Supp. 2005 Jan $1 ; 3(6): 1-7$.

18. de Groat WC. A neurologic basis for the overactive bladder. Urol. 1997;50(6A suppl):36-52. PMID 9426749.

19. Brading AF. Spontaneous activity of lower urinary tract smooth muscles: correlation between ion channels and tissue function. J Physiol. 2006;570:1322.

20. Drake MJ, Mills IW, Gillespie JI. Model of peripheral autonomous modules and a myovesical plexus in normal and overactive bladder function. Lancet. 2001;358:401-3.

21. Andersson KE. Detrusor myocyte activity and afferent signaling. Neurourol Urodyn. 2010;29:97106.

22. Howard B. Goldman, International Continence Society best practice statement for use of sacral neuromodulation, Neurourol Urodynam. 2018;1-26.

Cite this article as: Navarro JJA, Sánchez RDL, Uscanga OAM, Sosa MIT, Reyes FL, Vilchis JAB. Refractory hyperactive bladder treated with sacral neuromodulator: case report and literature review. Int J Reprod Contracept Obstet Gynecol 2018;7:293741. 